\title{
ADDENDUM
}

\section{Activating efficient phosphorescence from purely organic materials by crystal design}

Onas Bolton, Kangwon Lee, Hyong-Jun Kim, Kevin Y. Lin and Jinsang Kim

Nature Chemistry 3, 207-212 (2011); published online 13 February 2011; corrected after print 15 March 2011.

After the publication of this Article the authors found a further relevant paper that they would like to cite. The paper reports crystallization-induced rotational restriction of benzophenone derivatives and ensuing phosphorescence enhancement: Yuan, W. Z. et al. Crystallization-induced phosphorescence of pure organic luminogens at room temperature. J. Phys. Chem. C 114, 6090-6099 (2010). 